\title{
Regional Block versus General Anaesthesia for Caesarean Section and Neonatal Outcomes. A Clinical Comparative Study
}

\author{
Prabal Bharali ${ }^{1}$, Mrinal Kanti Taye ${ }^{2}$, Arunima Goswami ${ }^{3}$, Amio Kumar Deori ${ }^{4}$ \\ ${ }^{I}$ Department of Anaesthesiology and Critical Care, Gauhati, Medical College and Hospital, India \\ ${ }^{2}$ Department of Anaesthesiology and Critical Care, Gauhati Medical College and Hospital, India \\ ${ }^{3}$ Department of Pathology, Gauhati Medical College and Hospital, India \\ ${ }^{4}$ Department of Anaesthesiology and Critical Care, Assam Medical College and Hospital, India
}

\begin{abstract}
:
Introduction: Anaesthesia for caesarean section poses one of the most critical of all problems to the anaesthesiologist. Aim of the present study was to find out an anaesthetic technique for caesarean section in which the babies are delivered in better clinical condition employing Apgar scoring system. Patients and Methods: In the study 180 patients undergoing caesarean section were divided randomly into 3 groups consisting of 60 patients each according to the indication for caesarean section. .
\end{abstract}

Group1: elective post caesarean section.

Group 2: failure to progress (urgent section).

Group 3: fetal distress (emergency section).

In each group 30 patients were given regional block and 30 patients were given general anesthesia.

Results: At one minute when the Apgar score was compared for neonatal depression (Apgar score<7) between $G A$ and $R B$, there was no significant difference $(p>0.05)$ found in group 1 but in group 2 and 3 the difference was significant $(P<0.05)$. At five minutes the difference was non significant $(P>0.05)$ between both the techniques in all the three groups.

Conclusions: Both general anaesthesia and regional block appear equally safe for babies delivered by elective caesarean section but in unplanned cases regional block provides fetal advantages

Keywords: caesarean section, apgar score, regional anesthesia, fetal advantage.

\section{Introduction}

A woman in labour and consequently going for caesarean section poses one of the most critical of all problems to the anaesthesiologist. The hazard to two lives have to be considered.[1 ] The present study was done to find out an anaesthetic technique for caesarean section in which the babies are delivered in better clinical condition employing Apgar scoring system. Both general and regional anaesthesia found to be equally safe for babies delivered by elective caesarean section but in unplanned cases regional block provides fetal advantages.

\section{Materials and methods}

The present study is a prospective, randomized, single-blinded study conducted in Assam Medical College and Hospital, Dibrugarh from August'2010 to July'2011 with prior permission from the hospital authority and hospital ethical committee after fulfilling all the norms.

In the study 180 patients undergoing caesarean section were divided randomly into 3 groups consisting of 60 patients each. The groups were according to the indication for caesarean section.Group1: elective post caesarean section. Group 2:failure to progress (urgent section).Group 3:fetal distress (emergency section). In each group 30 patients were given regional anesthesia and 30 patients were given general anesthesia. Inclusion criteria: 1.Gestation 38th-41th completed weeks.2. Singleton pregnancy. 3.Non breech presenting live birth > 10 percentile of size of gestational age.4. Maternal age 20-44yrs. 5.Maternal weight 41-80 kg.6.Physical status ASA I \& II. Exclusion criteria:1. Pregnancies with reported hypertension. 2. Oligohydramnios and polyhydramnios.3.Antepartum hemorrhage.4.Suspected fetal abnormalities. Patient preparation: light diet on the night before surgery and Tab. Ranitidine $300 \mathrm{mg}$ orally and nil per orally for six hours in elective cases. Methods: written and informed consent were taken from all participants on the day of surgery. Baseline measures: demographic data, preoperative medications and surgical and medical history were taken from the patients and were recorded. Course of anaesthesia: For general anaesthesia: An intravenous line is established. Premedication with intravenous glycopyrrolate $0.2 \mathrm{mg}$ \& Ondansetron $4 \mathrm{mg}$ and preoxygenation with $100 \% 02$ for 3 minutes. Patients were position in a manner to achieve left uterine displacement. Patient induced with Propofol $(2 \mathrm{mg} / \mathrm{kg})$ and intubated with bolus dose of Succinylcholine $(1 \mathrm{mg} / \mathrm{kg})$ intravenously . Mask Ventilation were done with oxygen in elective cases. Laryngoscopies were done after 60 seconds and rapid sequence 
intubations were done in unplanned (urgent and emergency) cases. Anaesthesia were maintained with N20 \& 02(50:50) and isoflurane as neccesary. Normocarbia were maintained in all cases. Bolus dose of atracurium 0.5 $\mathrm{mg} / \mathrm{kg}$ were administered subsequently. Maintenance doses of relaxant at $1 / 5$ th of initial dose were administered. After delivery of the foetus, tramadol hydrochloride $1 \mathrm{mg} / \mathrm{kg}$ administerded intravenousely . Oxytocins were added to I.V. fluid. At completion of surgery reversal were done with neostigmine $0.05 \mathrm{mg} / \mathrm{kg} \mathrm{\&}$ glycopyrrolate $0.002 \mathrm{mg} / \mathrm{kg}$ intravenously by titration. For regional anaesthesia Pre loading with $20 \mathrm{ml} / \mathrm{kg}$ of crystalloid were done. With all aseptic measures $0.5 \%$ bupivacaine heavy $12 \mathrm{mg}$ were given intrathecally in L3-4 space with Quincky 25G needle in left lateral position in spinal procedures and $0.5 \%$ isobaric bupivacaine $15 \mathrm{ml}$ were given in L3-4 epidural space with 18G Touhy epidural needle and 20G catheter in epidural procedures. Oxygen inhalation via mask is given in 3-4L/min. Maternal hypotension were treated promptly with ephedrine 5-10mg I.V. and with intravenous fluids. Monitoring: Apgar score recorded during the study to evaluate the neonatal outcome. [table1]. Rating of neonatal condition were done by .a) No depression $\geq 7$. b) Depression $<7$.

Statistical analysis of data: The total sample size was 180 patients divided into 3 groups with 60 in each group. This was a randomized-controlled trial where randomization was achieved by computer-generated numbers. The sequence was generated by a statistician. Data were reported as mean $\pm \mathrm{SD}$, median, and $\mathrm{n}(\%)$ where ever appropriate. The demographic data were analyzed using students " $t$ " test and Chi-square test. Parametric and nonparametric data of the three groups were compared and analyzed using Student's t-test and the Mann-Whitney U-test, respectively. A 'p' value less than 0.05 ( $\mathrm{a}=0.05)$ was considered statistically significant. Data were analyzed using SPSS statistical software version 13.0.(SPSS Inc,Chicago, II,USA).

\section{Result and observation}

In this study, all patients were of age groups between 20-44 years and body weight of $41-80 \mathrm{~kg}$ undergoing caesarean section belonging to ASA I \& II physical status. The parameters taken into this study were apgar scores at one and five minutes.

Mean age in Group 1: $29.97 \pm 6.88$ and $29.83 \pm 7.51$; in Group 2: $30.70 \pm 6.13$ and $29.67 \pm 7.08$; in Group 3: $30.33 \pm 6.88$ and $29.43 \pm 7.24$ in general anesthesia and regional anaesthesia respectively. There is no significant difference in the age distribution pattern in our study and all groups had even distribution in relation to age. [table 2]

Mean weight in Group 1: $60.7 \pm 12.52$ and $60.57 \pm 11.3$; in Group 2: $60.87 \pm 12.5$ and $59.87 \pm 11.28$ while in Group 3: $\quad 61.07 \pm 12.65$ and $59.83 \pm 11.31$ in general anesthesia and regional block respectively. There is no significant difference in the weight distribution pattern in our study and all groups had even distribution in relation to weight [table 3].

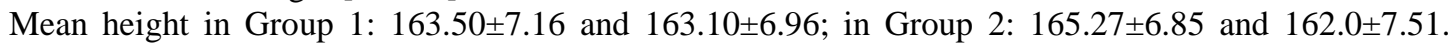
While in Group 3: $163.17 \pm 5.96$ and $163.83 \pm 6.85$ in general anesthesia and regional anaesthesia respectively. There is no significant difference in the height distribution pattern in our study and all groups had even distribution in relation to height. [Table 4]

When the apgar score at 1 minute was compared for neonatal depression ( apgar score $<7$ ) between GA and RB, in group 1 there was no significant difference $(p>0.05)$ but in group 2 and 3 there found significant difference between both techniques $(\mathrm{P}<0.05)$. [Table5,6,7]. There was no significant difference found between two techniques GA \& RB regarding 5 minutes apgar score and neonatal depression in group 1, 2 and 3. $(\mathrm{P}>0.05)$. [Table $8,9,10]$

Though in all three groups with regional anaesthesia shown more incidence of maternal hypotension (SBP <100mmHg) but there was no significant difference found between both technique in each group regarding maternal hypotension $(\mathrm{p}>0.05)$ in our study.[Table 11]

Table1. Apgar scoring system:

\begin{tabular}{|l|l|l|l|}
\hline \multirow{2}{*}{ Sign } & \multicolumn{2}{|c|}{ Scoring } \\
\cline { 2 - 4 } & 0 & 1 & 2 \\
\hline Respiratory effort & Absent & Slow, irregular & Good, crying \\
\hline Heart rate & Absent & Slow $(<100)$ & $>100$ \\
\hline Muscle tone & Flaccid & Flexion of extremities & Active body movements \\
\hline Reflex irritability & No response & Grimace & Cry \\
\hline Colour & Blue, pale & Body pink, extremity blue & Complete pink \\
\hline
\end{tabular}


Table 2. Age distribution in each group.

\begin{tabular}{|c|c|c|c|c|c|c|c|c|c|c|c|c|}
\hline \multirow{3}{*}{$\begin{array}{l}\text { Age } \\
\text { (in } \\
\text { years) }\end{array}$} & \multicolumn{4}{|c|}{ Group 1} & \multicolumn{4}{|c|}{ Group 2} & \multicolumn{4}{|c|}{ Group 3} \\
\hline & \multicolumn{2}{|c|}{ GA } & \multicolumn{2}{|l|}{$\mathrm{RB}$} & \multicolumn{2}{|c|}{ GA } & \multicolumn{2}{|l|}{$\mathrm{RB}$} & \multicolumn{2}{|c|}{ GA } & \multicolumn{2}{|l|}{ RB } \\
\hline & No. & $\%$ & No. & $\%$ & No. & $\%$ & No. & $\%$ & No. & $\%$ & No. & $\%$ \\
\hline $20-24$ & 9 & 30.0 & 8 & 26.67 & 6 & 20.0 & 8 & 26.67 & 9 & 30.0 & 12 & 40.0 \\
\hline $25-29$ & 7 & 23.33 & 7 & 23.33 & 8 & 26.67 & 10 & 33.33 & 6 & 20.0 & 5 & 16.67 \\
\hline $30-34$ & 5 & 16.67 & 6 & 20.0 & 7 & 23.33 & 4 & 13.33 & 6 & 20.0 & 4 & 13.33 \\
\hline $35-39$ & 6 & 20.0 & 7 & 23.33 & 7 & 23.33 & 5 & 16.67 & 6 & 20.0 & 7 & 23.33 \\
\hline $40-44$ & 3 & 10.0 & 2 & 6.67 & 2 & 6.67 & 3 & 10.0 & 3 & 10.0 & 2 & 6.67 \\
\hline TOTAL & 30 & 100.0 & 30 & 100.0 & 30 & 100.0 & 30 & 100.0 & 30 & 100.0 & 30 & 100.0 \\
\hline
\end{tabular}

Table -3: Weight distribution in each group.

\begin{tabular}{|c|c|c|c|c|c|c|c|c|c|c|c|c|}
\hline \multirow{3}{*}{$\begin{array}{l}\text { Weight (in } \\
\mathrm{Kg})\end{array}$} & \multicolumn{4}{|c|}{ Group 1} & \multicolumn{4}{|c|}{ Group 2} & \multicolumn{4}{|c|}{ Group 3} \\
\hline & \multicolumn{2}{|c|}{ GA } & \multicolumn{2}{|l|}{ RB } & \multicolumn{2}{|c|}{ GA } & \multicolumn{2}{|l|}{ RB } & \multicolumn{2}{|c|}{ GA } & \multicolumn{2}{|l|}{ RB } \\
\hline & No. & $\%$ & No. & $\%$ & No. & $\%$ & No. & $\%$ & No. & $\%$ & No. & $\%$ \\
\hline $41-50$ & 8 & 26.67 & 6 & 20.0 & 8 & 26.67 & 7 & 23.33 & 8 & 26.67 & 8 & 26.67 \\
\hline $51-60$ & 7 & 23.33 & 9 & 30.0 & 6 & 20.0 & 9 & 30.0 & 6 & 20.0 & 8 & 26.67 \\
\hline $61-70$ & 7 & 23.33 & 8 & 26.67 & 8 & 26.67 & 8 & 26.67 & 7 & 23.33 & 8 & 26.67 \\
\hline $71-80$ & 8 & 26.67 & 7 & 23.33 & 8 & 26.67 & 6 & 20.0 & 9 & 30.0 & 6 & 20.0 \\
\hline TOTAL & 30 & 100.0 & 30 & 100.0 & 30 & 100.0 & 30 & 100.0 & 30 & 100.0 & 30 & 100.0 \\
\hline
\end{tabular}

Table -4: Height distribution in each group

\begin{tabular}{|c|c|c|c|c|c|c|c|c|c|c|c|c|}
\hline \multirow{3}{*}{$\begin{array}{l}\text { Height (in } \\
\mathrm{cm} \text { ) }\end{array}$} & \multicolumn{4}{|c|}{ Group 1} & \multicolumn{4}{|c|}{ Group 2} & \multicolumn{4}{|c|}{ Group 3} \\
\hline & \multicolumn{2}{|c|}{ GA } & \multicolumn{2}{|l|}{ RB } & \multicolumn{2}{|c|}{ GA } & \multicolumn{2}{|l|}{ RB } & \multicolumn{2}{|c|}{ GA } & \multicolumn{2}{|l|}{$\mathrm{RB}$} \\
\hline & No. & $\%$ & No. & $\%$ & No. & $\%$ & No. & $\%$ & No. & $\%$ & No. & $\%$ \\
\hline $151-160$ & 12 & 40.00 & 14 & 46.67 & 8 & 26.67 & 16 & 53.33 & 10 & 33.33 & 8 & 26.67 \\
\hline $161-170$ & 10 & 33.33 & 8 & 26.67 & 12 & 40.00 & 10 & 33.33 & 14 & 46.67 & 16 & 53.33 \\
\hline $171-180$ & 8 & 26.67 & 8 & 26.67 & 10 & 33.33 & 4 & 13.33 & 6 & 20.00 & 6 & 20.00 \\
\hline TOTAL & 30 & 100.0 & 30 & 100.0 & 30 & 100.0 & 30 & 100.0 & 30 & 100.0 & 30 & 100.0 \\
\hline
\end{tabular}

Table -5: Apgar score at 1 min. with GA and RB in group 1

\begin{tabular}{|l|l|l|l|l|}
\hline \multirow{2}{*}{ Apgar score at 1 min. } & GA & RB \\
\cline { 2 - 5 } & No. $(\mathrm{n}=30)$ & $\%$ & No. $(\mathrm{n}=30)$ & $\%$ \\
\hline Apgar score $<7$ & 3 & 10.0 & 1 & 3.33 \\
\hline Apgar score $\geq 7$ & 27 & 90.0 & 29 & 96.67 \\
\hline
\end{tabular}

Table6. Apgar score at $1 \mathrm{~min}$ with GA and RB in group 2

\begin{tabular}{|l|l|l|l|l|}
\hline \multirow{2}{*}{ Apgar score at $1 \mathrm{~min}}$. & GA & RB & $\%$ \\
\cline { 2 - 5 } & No. $(\mathrm{n}=30)$ & $\%$ & No. $(\mathrm{n}=30)$ & 3.33 \\
\hline Apgar score $<7$ & 6 & 20.0 & 1 & 96.67 \\
\hline Apgar score $\geq 7$ & 24 & 80.0 & 29 & 29 \\
\hline
\end{tabular}

Table -7: Apgar score at 1 min. with GA and RB in group 3

\begin{tabular}{|l|l|l|l|l|}
\hline \multirow{2}{*}{ Apgar score at $1 \mathrm{~min}}$. & GA & $\%$ & RB & No. $(\mathrm{n}=30)$ \\
\cline { 2 - 5 } & No. $(\mathrm{n}=30)$ & 33.33 & 3 & 10.0 \\
\hline Apgar score $<7$ & 10 & 66.67 & 27 & 90.0 \\
\hline Apgar score $\geq 7$ & 20 & & 27 & \\
\hline
\end{tabular}

Table -8: Apgar score at 5 min. with GA and RB in group 1

\begin{tabular}{|c|c|c|c|c|}
\hline \multirow{2}{*}{ Apgar score at 5 min. } & \multicolumn{2}{|c|}{ GA } & \multicolumn{2}{c|}{ RB } \\
\cline { 2 - 5 } & No. $(\mathrm{n}=30)$ & $\%$ & No. $(\mathrm{n}=30)$ & 0 \\
\hline Apgar score $<7$ & 1 & 3.33 & 0 & 0.0 \\
\hline Apgar score $\geq 7$ & 29 & 96.67 & 30 & 100.0 \\
\hline
\end{tabular}

Table -9: Apgar score at 5 min. with GA and RB in group 2

\begin{tabular}{|l|l|l|l|l|}
\hline \multirow{2}{*}{ Apgar score at 5 min. } & GA & RB & $\%$ \\
\cline { 2 - 5 } & No. $(\mathrm{n}=30)$ & $\%$ & No. $(\mathrm{n}=30)$ & 0.0 \\
\hline Apgar score $<7$ & 1 & 3.33 & 0 & 100.0 \\
\hline Apgar score $\geq 7$ & 29 & 96.67 & 30 & \\
\hline
\end{tabular}

Table 10: apgar score at 5 min.with GA and RB in group 3

\begin{tabular}{|l|l|l|l|l|}
\hline \multirow{2}{*}{ Apgar score at 5 min. } & GA & RB & No. $(\mathrm{n}=30)$ & $\%$ \\
\cline { 2 - 5 } & No. $(\mathrm{n}=30)$ & $\%$ & 1 & 3.33 \\
\hline Apgar score $<7$ & 3 & 10.0 & 29 & 96.67 \\
\hline Apgar score $\geq 7$ & 27 & 90.0 & & \\
\hline
\end{tabular}


Regional Block Versus General Anaesthesia For Caesarean Section And Neonatal Outcomes...

Table 11: maternal hypotension (SBP <100mmhg) in each group.

\begin{tabular}{|c|c|c|c|c|c|c|c|c|c|c|c|c|}
\hline \multirow{3}{*}{$\begin{array}{l}\text { Intra operative SBP } \\
\text { before delivery of } \\
\text { the baby }\end{array}$} & \multicolumn{4}{|c|}{ Group 1} & \multicolumn{4}{|c|}{ Group 2} & \multicolumn{4}{|c|}{ Group 3} \\
\hline & \multicolumn{2}{|c|}{ GA } & \multicolumn{2}{|l|}{$\mathbf{R B}$} & \multicolumn{2}{|c|}{ GA } & \multicolumn{2}{|l|}{$\mathbf{R B}$} & \multicolumn{2}{|c|}{ GA } & \multicolumn{2}{|l|}{$\mathbf{R B}$} \\
\hline & No. & $\%$ & No. & $\%$ & No. & $\%$ & No. & $\%$ & No. & $\%$ & No. & $\%$ \\
\hline SBP $<100 \mathrm{mmHg}$ & 2 & 6.67 & 6 & 20.0 & 1 & 3.33 & 3 & 10.0 & 0 & 0.0 & 2 & 6.67 \\
\hline $\mathrm{SBP} \geq 100 \mathrm{mmHg}$ & 28 & 93.33 & 24 & 80.0 & 29 & 96.67 & 27 & 90.0 & 30 & $\begin{array}{l}100 . \\
0\end{array}$ & 28 & 93.33 \\
\hline
\end{tabular}

GA-General anaesthesia, RB-Regional block

\section{Discussion}

Various studies had been carried out by different workers for an acceptable method of anaesthesia with minimum disturbances in the mother and the newborn. In our study an attempt is being made to observe the efficiency between general anaesthesia and regional block for better neonatal outcome following caesarean section in terms of one and five minutes apgar scores.

One hundred Eighty (180) patients were divided into three groups with 60 (Sixty) patients in each group. The results and observations obtained from this study were compared in the light of observations of other workers. Premedication and anaesthetic techniques were kept constant in order to avoid variations in our observations.

To make the clinical assessment of the newborn the scoring system as evaluated by Apgar et al (1958) using five signs noted one minutes after birth is used.[2 ] The signs are heart rate, respiratory effort, muscle tone, reflex irritability and colour. Each sign is given a score of 0,1 or 2 . A total score of 10 shows that the infant is in the best possible condition. They recommended that the scoring system has been used as a guide to the need for resuscitation. Apgar score is the best parameter to assess the immediate condition of the baby (Drowning J.W et al 1997).[ 3]

Using Apgar scoring system for assessment of the newborn in our present series at one minute it has been seen that no baby could attain maximum score of 10 because no baby was found to score 2 for colour. Investigating this point Crawford (1962) used the scoring system as A - C (Apgar minus colour) and explained that most infants delivered vaginally loose one point for colour at one minute and most of those delivered by caesarean section loose two.[4]. In the vaginal delivery skin stimulation sustained by the infant help to attain the colour score of 2 earlier than caesarean section because of slighter rubbing of the baby skin in caesarean delivery.

For assessment of neonatal outcome we have taken one and five minutes interval after delivery because one minute after the birth of the baby represents the time of most severe depression but the five minutes apgar score has also been introduced in an attempt to give a rather more dynamic interpretation of the infants behavior following delivery and its responds to resuscitation.

We have attempted to keep the demographic variables(age, weight, height) similar as far as possible to standardize the results. The demographic characters of the patients in the study were comparable in all the groups. (Martin T.C. et al 2007 ; Abbound, T. K. et al 1985 and Kayacan, N. et al 2004)[ 5,6,7 ].

I-D and U-D times are the most important factors so far the wellbeing of the newborn is concerned.In our study, cases with I-D times less than 8 minutes and U-D times less than 90 seconds were included because these are the most appropriate times to deliver the infant without depression. ( Ehrenkranz, R.A et al 2003; Niermeyer, $S$ et al 2001)[8,9].

Most of the reports in the literature suggest that maternal blood pressure prior to delivery is one important factor affecting the fetus. But if recognized and treated promptly transient maternal hypotension should not be associated with neonatal depression (Norris, M.C 1987)[10].In our study, though the incidence of maternal hypotension were higher with regional block but there were found no significant difference in maternal hypotension between both techniques and unlikely to affect the neonatal outcomes [Table 11].

Most of the drugs used before the delivery of the fetus cross the placenta. Propofol readily cross the placenta but is rapidly cleared from neonatal circulation (Dailland et al 1989)[11]. Succinylcholine in doses used in our study is unlikely to cross placenta sufficiently to effect the baby as reported by also Moya and Krisselgaard in 1961.[12] Similarly atracurium used in doses in our study without any adverse effect measured by apgar score (Flynn, P.J et al1984)[13]. Anaesthesia was maintained with isoflurane $0.5 \%$ in a $50 \%$ oxygennitrous oxide mixture. Normocarbia was maintained at around $30 \mathrm{mmHg}$ with general anaesthesia. They do not depress the newborn in brief exposure in caesarean section. (Hughes, S.C et al 2001; Farragher, R.A et al 2003).[14,15].

The concentration and volume of bupivacaine used in spinal anaesthesia and epidural anaesthesia were $0.5 \%$ bupivacaine heavy $12 \mathrm{mg}$ and $0.5 \%$ isobaric bupivacaine $15 \mathrm{ml}$ respectively. These doses used in regional block were without any apparent infant problems. (Norris,et al 1988; Mc Guiness,G.A 1978).[ 16 ]

The incidence of depressed newborns in the present series in group 1 at one minute were $10 \%$ in general anaesthesia and $3.33 \%$ with regional block. There was no significant difference found between both 
Regional Block Versus General Anaesthesia For Caesarean Section And Neonatal Outcomes...

techniques $(\mathrm{p}>0.05)$. These findings are consistent with that of James, F.M. et al 1977; Zygorzychi, M.T. et al 1982; Evan C.M. et al 1993 and Sukhera, S.A. et al 2006.[17,18,19,20].Also in five minutes no baby was depressed (Apgar score <7) with regional block and only one baby was found depressed (3.33\%) with general anaesthesia in group1. These findings are consistent with that of Qublan, H.S et al 2001; Imtiaz,A et al 20010 and Algert, C.S. et al 2009.[ 21,22,23 ]

In the present study, in group 2, $20 \%$ babies were depressed with general anaesthesia comparing with $3.33 \%$ depressed babies with regional block. A significantly better neonatal outcome was found after regional block in group 2. This similar finding was also observed by Ong, B.Y. et al in 1989 in their comparative study of general and regional anaesthesia for caesarean section effects on neonates [24]. Regarding neonatal depression at five minutes in group 2, no baby was found depressed with regional block and only one baby (3.33\%) was depressed with general anaesthesia. There was no significant difference found between both the techniques which is consistent with the findings of Algert,C.S et al 2009.In group 3, when the incidence of neonatal depression were compared, there were $33 \%$ babies found depressed with general anaesthesia and $10 \%$ babies were depressed with regional block at one minute. One minute Apgar score < 7 were significantly better following regional block despite the presence of fetal distress. Similar finding were observed in other studies like Marx, G.F. et al 1984; Ong, B.Y. et al 1989 and Afolabi, B.B. et al in 2003[25,26]. There were no significant differences found in neonatal outcome between both techniques at five minutes in group 3 . There were three babies found depressed with general anaesthesia $(10.0 \%)$ and only one baby in regional technique (3.33\%). These findings were almost similar with findings of Ramanathan et al 1988 and Algert, C.S.et al in $2009[27$ ].

\section{Conclusion}

Obstetrical anaesthesia is a fast growing speciality and is accompanied by its special problems. Anaesthesia has the effects on both the mother and the fetus. Both general anaesthesia and regional block appear equally safe for babies delivered by elective caesarean section but in unplanned cases regional block provides fetal advantages even in the presence of fetal distress specially in terms of short term neonatal outcome.

\section{References}

[1]. Wylie and Churchill-Davidson's A PRACTICE OF ANAESTHESIA, 6th Ed. Edited by Thomas E.J. Healy and Peter J. Cohen. Edward Arnold, London, 1996. Page 1282.

[2]. Apgar V,Holaday D, James LS, Weisbrot IM, Berrein C. Evaluation of the newborn infant; second report. J Am Med Assoc. 1958 13;168(15):1985-8

[3]. Drowning J.W., Houlton P.C., Barclay A., Extradural anaesthesia for C.S.: A comparison with G.A. Br. J. Anaesth. 1997; 51:390394.

[4]. Crawfort JS.Anaesthesia for caesarean section: a proposal for evaluation, with analysis of a method. Br J Anaesth. 1962;34:179-94.

[5]. Martin T.C.; Bell T.; OgunbiyiO.Comparison of GA and RA for CS in Antigua and Barbuda: West Indian Med. J. 2007; 56(4):330333.

[6]. Abboud TK, Nagappala S, Murakawa K, David S, Haroutunian S, Zakarian M et al. Comparison of the effects of general and regional anesthesia for cesarean section on neonatal neurologic and adaptive capacity scores. AnesthAnalg. 1985;64(10):996-1000.

[7]. Kayacan N; Bigat Z; Yegin A .A randomized prospective study on the maternal and neonatal outcome of epidural, combined spinal epidural and general anaesthesia for elective C.S; TurkiyeKlinikleri. J. Med.Sci 2004,24:476-482.

[8]. Ehrenkranz R.A., Wright L.L., editors highlights from the NICHD neonatal research network. Semin perinatal 2003;23(4): 335-348.

[9]. Niermeyer S., Keenan W. Resuscitation of the newborn infant. In: Klaus M.H. Fanaroff AA, editors. Care of high risk neonate, 5th Ed., Philadelphia W.B. Saunders; 2001 pp 45-61.

[10]. Norris MC. Hypotension during spinal anesthesia for caesarean section: Does it affect neonatal outcome? RegAnaesth1987;12:1913.

[11]. Dailland P1, Cockshott ID, Lirzin JD, Jacquinot P, Jorrot JC, Devery JHarmey.Intravenous propofol during cesarean section: placental transfer, concentrations in breast milk, and neonatal effects. A preliminary study. Anesthesiology. 1989 ;71(6):827-34.

[12]. Krisselgaard N. Mya F. Investigation of placental threshold to succinylcholine. Anaesthesiology 1961;22:7-10.

[13]. Flynn P.J.; Frank M.; Hughes R. Use of Atracurium in C.S. Br J Anaesth. 1984;56(6):599-605.

[14]. Hughes S.C Levinson G., Rosen M.A., Shnider and Levinson's Anaesthesia for Obstetrics 4th Ed.2001 Page 217,221.book

[15]. FarragharR.A\&KodaliB.S-Wylie\&Churchill-Davidson-A practice of anesthesia 7th ed.pp-931.book

[16]. McGuinness GA, Merkow AJ, Kennedy RL, Erenberg A. Epidural anesthesia with bupivacaine for Cesarean section: Neonatal blood levels and neurobehavioral responses. Anesthesiology. 1978;49:270-3.

[17]. James FM 3rd, Crawford JS, Hopkinson R, Davies P, Naiem H.A comparison of general anesthesia and lumbar epidural analgesia for elective cesarean section. AnesthAnalg. 1977 ;56(2):228-35.

[18]. Zyqorzychi MT, Brinkman C.R. The effect of G.A. \& E.A. upon neonatal apgar scores in repeat C.S. Surgery, Gynecology \& Obstetrics[1982, 155(5):641-645]

[19]. Evans CM1, Murphy JF, Gray OP, Rosen M. Epidural versus general anaesthesia for elective caesarean section. Effect on Apgar score and acid-base status of the newborn. Anaesthesia. $1989 ; 44(9): 778-82$.

[20]. Sukhera S.A. Saleem A. A comparison between epidural and general anaesthesia for elective C.S Professional Med. J. 2006; 13(1): $72-78$.

[21]. Qublan H.S. Merhej A. Daddas M.A. Hindawi I.M. Spinal versus general anaesthesia for C.S. Clin Exp. Obst. Gynae 2001;28(4)246-48

[22]. Imtiaz A, Mustafa S, Masroorudin, noor-ul-huq, Ali S H, Imtiaz K. Effect of spinal and general anaesthesia over apgar score in neonates born after elective cesarean section. J L U M H S, 2010;9(3);151-54 
[23]. Charles S Algert,1Jennifer R Bowen,2Warwick B Giles,Greg E Knoblanche,Samantha J Lain,1 and Christine L Roberts.Regional block versus general anaesthesia for caesarean section and neonatal outcomes: a population-based study. BMC Med. 2009; 7: 20. Published online 2009 Apr 29. doi: 10.1186/1741-7015-7-20 .

[24]. Ong B.Y. Cohen M.M. Palahniuk R.J. Anaesthesia for C.S. - effects on neonates. Anaesth. Analg. 1989;68:270-78

[25]. Marx G.F.; Luylex W.M.; Cohen S.E. Fetal neonatal status following C.S. for fetal distress. Br. J. Anaesth (1984); 56:1009-13.

[26]. Afolabi B.B.; Kaka A.; Abudu O.O.: Spinal and General Anaesthesia fo emergency C.S.; effect on the neonatal apgar score; Niger Post. Grad. Med. J. 2003, Mar 10(1): 51-55.

[27]. Ramanathan J, Ricca D.M, Sibai B.M, Angel JJ. Epidural vs general anesthesia in fetal distress with various abnormal fetal heart rate pattern.Anesth.Analg1988;7:147-152. 